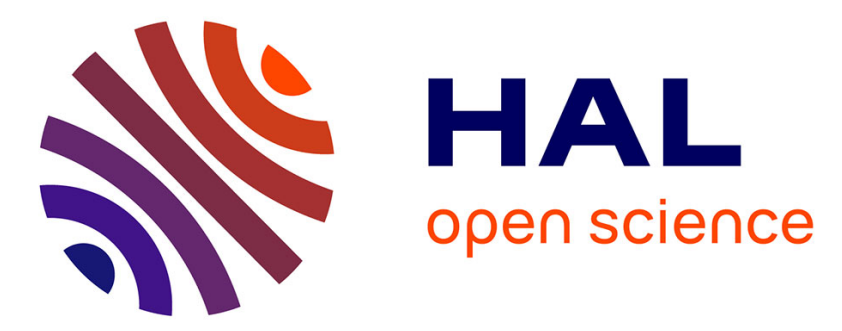

\title{
Comprehensive Evaluation of Soil Fertility in Yanzhou District Based on Principal Component Analysis
}

\author{
Qiuting Zhang, Xia Geng
}

\section{To cite this version:}

Qiuting Zhang, Xia Geng. Comprehensive Evaluation of Soil Fertility in Yanzhou District Based on Principal Component Analysis. 11th International Conference on Computer and Computing Technologies in Agriculture (CCTA), Aug 2017, Jilin, China. pp.86-93, 10.1007/978-3-030-06179-1_9 . hal-02111563

\section{HAL Id: hal-02111563 \\ https://hal.inria.fr/hal-02111563}

Submitted on 26 Apr 2019

HAL is a multi-disciplinary open access archive for the deposit and dissemination of scientific research documents, whether they are published or not. The documents may come from teaching and research institutions in France or abroad, or from public or private research centers.
L'archive ouverte pluridisciplinaire HAL, est destinée au dépôt et à la diffusion de documents scientifiques de niveau recherche, publiés ou non, émanant des établissements d'enseignement et de recherche français ou étrangers, des laboratoires publics ou privés. 


\title{
Comprehensive Evaluation of Soil Fertility in Yanzhou District Based on Principal Component Analysis
}

\author{
Qiuting Zhang ${ }^{1,2}$, Xia Geng $^{1,2(\bowtie)}$ \\ ${ }^{1}$ College of Information Science and Engineering, Shandong Agricultural University, Taian \\ Shandong, China \\ ${ }^{2}$ National Engineering Research Center for Information Technology in Agriculture,Beijing, \\ China \\ Zhang_qiutingere163.com, \\ gxesdau.edu.cn
}

\begin{abstract}
Soil fertility is the basis of sustainable agricultural development. Scientific and rational evaluation of soil fertility can better promote the development of agricultural informatization and modernization. Based on the data of 166 soil samples in Yanzhou District in 2014, the effects of $\mathrm{pH}, \mathrm{OM}, \mathrm{AN}, \mathrm{AP}$ and $\mathrm{AK}$ were chosen as evaluation indexes, SPSS was used to analyze the soil fertility status. The results showed that the overall level of soil fertility was below the medium: Among the 166 samples, there were 149 in the medium and low fertility, accounting for $89.76 \%$. The content of soil OM and AN was in medium and slightly lower level. In view of the above results, organic fertilizer, humic acid and nitrogen fertilizer should be added. Soil AP and AK content was in the middle and above the level, so the fertilizer could be maintained in order to achieve balanced fertilization.
\end{abstract}

Keywords: principal component analysis - Yanzhou district $\cdot$ comprehensive evaluation $\cdot$ soil fertility

\section{Introduction}

Comprehensive evaluation of soil fertility, can not only balance the fertilization but also improve the utilization efficiency of water and fertilizer of cultivated land. It can also improve the field management and provide a theoretical basis for the precise management of soil nutrients and rational use of soil resources. Moreover, it can minimize harm to the environment so it is of great significance for the protection of agricultural ecological environment and for the sustainable development of agriculture $[1,2,3]$. In recent years, more and more scholars have applied mathematical statistics to the quantitative study of soil fertility: Cluster analysis [4,5,6], factor analysis $[7,8,9]$, and principal component analysis $[10,11,12]$ have been widely used in soil fertility evaluation. There are many indexes affecting soil fertility, and they have certain correlation that may lead to overlap of information in the index. However, the principal component analysis method can overcome the correlation and overlap and use fewer indexes to replace the original more indexes. Meanwhile, the method can give an objective weighting based on the relative importance among the indicators, so as to avoid the subjective influence of the comprehensive evaluator. Now, the principal

* Corresponding author: Xia Geng, School of Information Science and Engineering, Shandong Agricultural University, Tai'an, China 
component analysis method has been widely used more and more. Therefore, this paper carried a comprehensive evaluation of soil fertility in Yanzhou district by principal component analysis based on the previous studies and selected three categories indexes that can be measurable, such as soil nutrition index, soil biology index and soil environment index, specifically selected available nitrogen(AN), available phosphorus(AP), available potassium(AK), organic matter( $\mathrm{OM})$ and $\mathrm{pH}$ to realize the comprehensive and quantitative evaluation of soil fertility.

\section{General Situation of Study Region}

Yanzhou District is located in the northeastern part of Jining City, Shandong Province, and located between northern latitude $35^{\circ} 23^{\prime} 31^{\prime \prime}$ and $35^{\circ} 43^{\prime} 17^{\prime \prime}$ and between east longitude $116^{\circ} 35^{\prime} 21^{\prime \prime}$ and $116^{\circ} 53^{\prime} 36^{\prime \prime}$ east in longitude. The total land area is 534.82 square kilometers and the basic farmland area is 2.8110 million hectares. The cultivated land area is 3.1769 million hectares, accounting for $59.40 \%$ of the total land area of the district. Yanzhou administers 4 subdistricts and 6 towns. The climate is warm temperate East Asian continental monsoon climate. The annual average temperature is 14.1 degrees centigrade, the average annual precipitation is $681 \mathrm{~mm}$ and the annual total sunshine are 2635.0 hours. There are 177 days in a year without frost. It is located in piedmont plain where belongs to the middle mountainous region of Taiyi mountain's southwest of Shandong Province. Plain area is 64670 hectares, accounting for 99.7\% of the total area. Soil types are divided into cinnamon soil, fluvo-aquic soil, lime concretion black soil 3 categories, 5 sub-categories, 7 soil genus, 30 soil species.

Among them, fluvo aquic soil is the main soil type, accounting for $76.24 \%$ of the total cultivated land area, $18.69 \%$ of sandy black soil and $5.07 \%$ of fluvo aquic soil.

\section{Research Method}

\subsection{Determination of Study Scope}

Xinyan town ranked first for the comprehensive economic strength among all towns of Jining City, Xiaomeng town is an important grain production base, and has the reputation of "Northwest granary" in Yanzhou, Caohe town is located in the northernmost of Yanzhou District and Da'an town is a national ecological town and is a national key town. These four towns are all located around the urban district of Yanzhou and they are concentrated in population and agricultural activities, so the four towns are used as sampling areas.

\subsection{Sample Analysis}

The data comes from the results of the plowed layers soil sampling in 2014. There are 166 sampling sites in Yanzhou District. According to the land use type and applicable conditions, the surface soil samples of $0 \sim 20 \mathrm{~cm}$ depth were collected around the survey sites by GPS positioning technology, and the soil samples which were equivalent to more than $3 \mathrm{~kg}$ of dry soil were retained. The collected soil samples were brought back to the laboratory and dried, ground and sieved in a cool ventilated place and then keep it for later use. Analysis method is based on the Agricultural Technology Extension Service Center of the Ministry of agriculture compiled " The investigation and quality evaluation of cultivated land productivity ". Soil $\mathrm{pH}$ was measured by potentiometry, OM was measured by potassium dichromate oxidation-external heating method, AN was measured by alkaline hydrolysis diffusion method, AP was measured by sodium bicarbonate extraction Mo-Sb colorimetry and $\mathrm{AK}$ was measured by ammonium acetate flame photometric method.

\section{Data Processing and Analysis}

\subsection{Data Processing}

Traditional (general) statistical analysis. The soil nutrient contents of 166 soil samples were statistically analyzed by SPSS. 
Principal component analysis. Standardize the raw data, establish the correlation coefficient matrix of the index, find the characteristic roots and eigenvectors of the correlation coefficient matrix, determine the number of principal components by the cumulative variance contribution rate, find the principal component.

\subsection{Traditional Statistical Analysis of Soil Fertility}

166 soil sample data which collected from Yanzhou District, Jining City, Shandong province were analyzed by using the SPSS statistical analysis software. (shown in Table 1.). The soil $\mathrm{pH}$ content was $6.800 \sim 7.200$, the average was 7 . The OM content of $6.142 \sim 24.759 \mathrm{~g} / \mathrm{kg}$, the average was $14.980 \mathrm{~g} / \mathrm{kg}$. AP and AK value were $9.850 \sim$ $92.025 \mathrm{mg} / \mathrm{kg}$ and $37.466 \sim 270.908 \mathrm{mg} / \mathrm{kg}$, the average was $30.044 \mathrm{mg} / \mathrm{kg}$ and 118.584 $\mathrm{mg} / \mathrm{kg}$ respectively. The content of AN was $35 \sim 238 \mathrm{mg} / \mathrm{kg}$, and the mean value was $84.467 \mathrm{mg} / \mathrm{kg}$.

Table 1. Traditional statistical data of soil nutrients in YanZhou District

\begin{tabular}{lllllllll}
\hline Indexs & $\begin{array}{c}\text { Max- } \\
\text { imum }\end{array}$ & $\begin{array}{l}\text { Min- } \\
\text { imum }\end{array}$ & Average & $\begin{array}{c}\text { Standard } \\
\text { deviation }\end{array}$ & $\begin{array}{l}\text { Coefficient } \\
\text { of variation }\end{array}$ & Skewness & $\begin{array}{l}\text { Peak } \\
\text { value }\end{array}$ & Median \\
\hline $\begin{array}{l}\mathrm{OM} \\
\mathrm{g} / \mathrm{kg}\end{array}$ & 24.759 & 6.142 & 14.980 & 2.983 & 19.916 & 0.114 & 0.928 & 15.081 \\
$\mathrm{pH}$ & 7.200 & 6.800 & 7.007 & 0.141 & 2.019 & -0.106 & -1.344 & 7.000 \\
$\mathrm{AN}$ & 238.000 & 35.000 & 84.467 & 27.303 & 32.324 & 1.753 & 6.801 & 84.000 \\
$\mathrm{mg} / \mathrm{kg}$ & & & & & & & & \\
$\begin{array}{l}\mathrm{AP} \\
\mathrm{mg} / \mathrm{kg}\end{array}$ & 92.025 & 9.850 & 30.044 & 16.659 & 55.450 & 1.391 & 2.033 & 26.563 \\
$\begin{array}{l}\mathrm{AK} \\
\mathrm{mg} / \mathrm{kg}\end{array}$ & 270.908 & 37.466 & 118.584 & 37.441 & 31.573 & 1.205 & 3.201 & 118.162 \\
\hline
\end{tabular}

The description of the 166 soil nutrients (Table 1.) showed that the spatial distribution of soil nutrients in the sample area is not uniform. The distribution of AK in all indicators had tremendous difference, the maximum value was 7.03 times of the minimum value. The distribution of the remaining nutrients was as follows: AN> AP> OM> pH, AN: $203.000 \mathrm{mg} / \mathrm{kg}$, AP $82.175 \mathrm{mg} / \mathrm{kg}$, OM $18.616 \mathrm{~g} / \mathrm{kg}, \mathrm{pH} 0.400$. The dispersion degree of soil spatial variability is usually expressed as the standard deviation or relative standard deviation (coefficient of variation) of a series of measurements. It is often considered that when the coefficient of variation less than or equal to $10 \%$ is weak variability, when the coefficient of variation more than $10 \%$ and less than $100 \%$ is moderate variability, when the coefficient of variation more than or equal to $100 \%$ is strong variability. Results showed that the spatial variability of soil nutrients follows the order of AP AN AK OM pH. Except for the weak variation of $\mathrm{pH}$ in soil nutrients, all of them were between $10 \%$ and $100 \%$, which were moderately variable. The coefficient of variation showed biggest variations of soil nutrients was AP. The maximum value of AP was 9.3 times of the minimum value. And the variation degree of $\mathrm{pH}$ was the smallest in totally five indicators. Therefore, the spatial distribution of soil nutrients in Yanzhou district was uneven.

Based on the grading standards of the second national soil survey grading standards (national soil survey office, 1992), the contents of OM and AN in Yanzhou district were below the medium level(up to level four), the content of AP was rich (more than 20 $\mathrm{mg} / \mathrm{kg}$, up to level two), high potassium content (more than $100 \mathrm{mg} / \mathrm{kg}$, up to level three). Soil organic matter, an important source of soil elements, especially nitrogen and phosphorus, has the capacity of improving soil retention of water and fertilizer and raising soil buffer capacity. Generally speaking, the amount of soil organic matter is an important indicator of soil fertility. On the basis of the analysis of the data, it can be seen that the content of soil organic matter in Yanzhou district is medium and slightly lower. Therefore, organic fertilizer and humic acid should be added. Nitrogen fertilizer should be applied in nitrogen deficient soil to promoting growth and development of crop. The content of available phosphorus and available potassium in the soil was in the middle and above level, so the fertilization amount can be maintained to achieve the balanced fertilization. 


\subsection{Principal Component Analysis}

Principal component analysis should first standardize the original data, and then establish the correlation coefficient matrix of variables. The correlation coefficient matrix was shown in Table 2.

Table 2. Correlation coefficient matrix

\begin{tabular}{lllllll}
\hline Indexes & Correlation & $\mathrm{pH}$ & $\mathrm{OM}$ & $\mathrm{AN}$ & $\mathrm{AP}$ & $\mathrm{AK}$ \\
\hline $\mathrm{pH}$ & Pearson & 1.000 & 0.132 & 0.088 & 0.082 & 0.089 \\
$\mathrm{OM}$ & Pearson & & 1.000 & 0.064 & 0.105 & $0.386^{* *}$ \\
$\mathrm{AN}$ & Pearson & & & 1.000 & 0.007 & 0.128 \\
$\mathrm{AP}$ & Pearson & & & & 1.000 & 0.051 \\
$\mathrm{AK}$ & Pearson & & & & & 1.000 \\
\hline
\end{tabular}

** correlation is significant at the 0.01 level(2-tailed)

Initial factor load matrix showed that (Table 3.), organic matter and available potassium had a greater positive load on the first principal component, indicating that organic matter and available potassium content were the most important factors affecting soil fertility. Available phosphorus has a greater positive load on the second principal component, indicating that available phosphorus is also an important factor affecting soil fertility.

Table 3. Initial factor load matrix and eigenvector

\begin{tabular}{ccccc}
\hline Indexes & \multicolumn{2}{c}{ Principal component } & \multicolumn{2}{c}{ Eigenvector } \\
& 1 & 2 & A1 & A2 \\
\hline $\mathrm{pH}$ & 0.42 & 0.29 & 0.34 & 0.29 \\
$\mathrm{OM}$ & 0.76 & -0.03 & 0.62 & -0.03 \\
$\mathrm{AN}$ & 0.35 & -0.44 & 0.28 & -0.44 \\
$\mathrm{AP}$ & 0.30 & 0.82 & 0.24 & 0.81 \\
$\mathrm{AK}$ & 0.75 & -0.25 & 0.60 & -0.25 \\
\hline
\end{tabular}

\subsubsection{Extract Principal Component}

The standardized data were analyzed by principal component analysis. According to the principle that the eigenvalue is greater than 1, two principal components are selected. The contribution of first principal component to soil fertility was $30.5 \%$. The cumulative variance contribution rate of the first 2 components reached $50.6 \%$. Due to it reflected the original 5 fertility elements of the majority of the information, it is reliable to use principal component analysis to study the soil fertility in Yanzhou district.

Table 4. Eigenvalue and variance contribution rate table

Total Variance Explained

\begin{tabular}{ccccccc}
\hline & \multicolumn{5}{c}{ Initial Eigenvalues } & \multicolumn{3}{c}{ Extraction Sums of Squared Loadings } \\
Component & Total & \%of Variance & Cumulative \% & Total & \% of Variance & Cumulative\% \\
\hline 1 & 1.523 & 30.462 & 30.462 & 1.523 & 30.462 & 30.462 \\
2 & 1.005 & 20.107 & 50.569 & 1.005 & 20.107 & 50.569 \\
3 & 0.984 & 19.678 & 70.247 & & & \\
4 & 0.885 & 17.704 & 87.951 & & & \\
5 & 0.602 & 12.049 & 100.000 & & & \\
\hline
\end{tabular}

\subsubsection{Principal Component Score and Comprehensive Score}

Finally, factor scores were calculated. The variance contribution rate of each factor accounted for the proportion of the total variance contribution rate of two factors were used as weights to obtain a composite score.

$$
\begin{aligned}
& F_{1}=0.34 * X_{1}+0.62 * X_{2}+0.28 * X_{3}+0.24 * X_{4}+0.60 * X_{5} \\
& F_{2}=0.29 * X_{1}-0.03 * X_{2}-0.44 * X_{3}+0.81 * X_{4}-0.25 * X_{5}
\end{aligned}
$$




$$
F=0.305 * F_{1}+0.201 * F_{2}
$$

Among them, $\mathrm{X}_{1}$ represents $\mathrm{pH}, \mathrm{X}_{2}$ represents $\mathrm{OM}, \mathrm{X}_{3}$ represents $\mathrm{AN}, \mathrm{X}_{4}$ represents $\mathrm{AP}$ and $\mathrm{X}_{5}$ represents $\mathrm{AK}$.

The results showed that the comprehensive scoring range was between -1.99 and 3.64. According to the range of comprehensive score, the soil fertility was divided into the following 3 grades(table 5): high fertility type( $\mathrm{F} \geq 1)$, medium fertility type $(0<\mathrm{F}<1)$, low fertility type $(\mathrm{F} \leq 0)$. Among the 166 valid data, the number of samples in high fertility group was 17 , accounting for only $10.24 \%$. The number of samples in low fertility group was 84 , accounting for $50.60 \%$. The sample of medium fertility group was 65 , and the proportion was $39.16 \%$ by principal component analysis. Xinyan Town, Da'an Town and Xiaomeng Town's low fertility type accounted for the highest proportion. There were 32 low fertility types in 53 samples of Xinyan Town, accounting for $60.38 \%$. There were 21 low fertility types in 38 samples of Daan Town, accounting for $55.26 \%$. There were 19 low fertility types in 42 samples, accounting for $45.24 \%$. This showed that the three towns had lower soil fertility. The highest proportion of Caohe town was the middle fertility type. There were 18 medium fertility types in 33 samples, accounting for $55.26 \%$, more than half, so the soil fertility of Caohe town belonged to medium level.

Table 5. Sample number and proportion of fertility level

\begin{tabular}{|c|c|c|c|c|}
\hline $\begin{array}{c}\text { Fertility } \\
\text { level }\end{array}$ & $\begin{array}{l}\text { Town's } \\
\text { name }\end{array}$ & Sample number & $\begin{array}{c}\text { Sample } \\
\text { size }\end{array}$ & Proportion $\%$ \\
\hline \multirow{10}{*}{$\begin{array}{c}\text { low } \\
\text { fertility } \\
\text { type } \\
(\mathrm{F} \leq 0)\end{array}$} & \multirow{3}{*}{$\begin{array}{l}\text { Xinyan } \\
\text { Town }\end{array}$} & 161721222325262731323435 & \multirow{4}{*}{32} & \multirow{4}{*}{19.28} \\
\hline & & 363740414446474850515657 & & \\
\hline & & 5859606364666768 & & \\
\hline & \multirow{2}{*}{ Da'an Town } & 135769707273747576798081 & & \\
\hline & & 83858789919295 & \multirow[t]{2}{*}{21} & \multirow[t]{2}{*}{12.65} \\
\hline & Caohe & 101112101103104108113114 & & \\
\hline & Town & 123114125 & \multirow[t]{3}{*}{12} & \multirow[t]{3}{*}{7.23} \\
\hline & \multirow{3}{*}{$\begin{array}{l}\text { Xiaomeng } \\
\text { Town }\end{array}$} & 14128129130133134135136137 & & \\
\hline & & 138140141142143151152153163 & & \\
\hline & & 164 & \multirow[t]{2}{*}{19} & \multirow[t]{2}{*}{11.45} \\
\hline \multirow{7}{*}{$\begin{array}{c}\text { medium } \\
\text { fertility } \\
\text { type } \\
(0<\mathrm{F}< \\
1)\end{array}$} & Xinyan & 181920242829303338424345 & & \\
\hline & Town & 49525355616265 & 19 & 11.45 \\
\hline & Da'an Town & 246871777884889093949697 & 14 & 8.43 \\
\hline & Caohe & 999100102106107109110111 & & \\
\hline & Town & 112115116118119120121126127 & 18 & 10.84 \\
\hline & Xiaomeng & 1315131144147149155156158 & & \\
\hline & Town & 159160162166 & 14 & 8.43 \\
\hline \multirow{7}{*}{$\begin{array}{l}\text { high } \\
\text { fertility } \\
\text { type } \\
(\mathrm{F} \geq 1)\end{array}$} & Xinyan & & & \\
\hline & Town & 3954 & 2 & 1.20 \\
\hline & Da'an Town & 828698 & 3 & 1.81 \\
\hline & Caohe & & & \\
\hline & Town & 105117122 & 3 & 1.81 \\
\hline & Xiaomeng & & & \\
\hline & Town & 132145146148150154157161165 & 9 & 5.42 \\
\hline
\end{tabular}

\section{Conclusion and Discussion}

The spatial distribution of soil nutrient in Yanzhou district was uneven. Results showed that the spatial variability of soil nutrients follow the order of AK AN AK OM pH. According to the variation degree of soil nutrient, OM accounted for $19.916 \%$, AN accounted for $32.324 \%$, AP accounted for $55.450 \%$, AK accounted for $31.573 \%$. Therefore $\mathrm{OM}$ and $\mathrm{AN}$ and $\mathrm{AP}$ and $\mathrm{AK}$ belonged to moderate variability. While $\mathrm{pH}$ 
accounted for $2.019 \%$, belonged to weak variability.

The soil OM and AN of cultivated land in Yanzhou district was medium and slightly lower. Therefore, the organic fertilizer, humic acid and nitrogen fertilizer should be added. The contents of AP and AK in soil were in the middle or higher level, and the amount of fertilizer remained unchanged, so as to achieve balanced fertilization. The soil fertility level in Yanzhou district was lower than the medium. According to the principal component analysis, the sample number of medium fertility type was 149 , accounting for $89.76 \%$ in total 166 samples. Meanwhile the soil samples with high fertility level were 17 and only accounting for $10.24 \%$.

In the three types, the proportion of low fertility type was highest in Xinyan town, Da'an town and Xiaomeng town, which was $60.38 \%, 55.26 \%, 45.24 \%$ respectively, showing that the soil fertility of these towns were relatively low; in Caohe town town, medium fertility type accounted for the greatest proportion, the number of which was 18 samples, accounting for $55.26 \%$ in total 33 samples, therefore the soil fertility of Caohe town belonged to the middle level.

Acknowledgment. This work was supported by the open research project of the National Engineering Research Center for Information Technology in Agriculture (KF2014W51-059).

\section{References}

1. Luo, D.Q., Bai, J., Xie, D.T.: Research on Evaluation Norm and Method of Soil Fertility. J. Soil and Environmental Sciences. 11(2), 202-205 (2002)

2. Wang, Z.L.: Study on Comprehensive Evaluation and Spatial Variability of Soil Fertility on Sanjiang Plain. Northeast Agricultural University. (2008)

3. Huang, A., Yang, L.A., Du, T., Wang, L.A., Zhang, B., Yuan, G.: Comprehensive Assessment of Soil Nutrients Based on PCA. J. Arid Zone Research. 31(5), 819-825 (2014)

4. Wen, Y.C., Li, Y.Q., Yuan, L., Li, J., Li, W., Lin, Z.A., Zhao, B.Q.: Comprehensive Assessment Methodology of Characteristics of Soil Fertility under Different Fertilization Regimes in North China. J. Transacions of the Chinese Society of Agricultural Engineering. 31(7), 91-99 (2015)

5. Zhu, Y.L.: Studies on Temporal and Spatial Variability of the Major Soil Fertility in Hebei Province. Agricultural University of Hebei. (2014)

6. Chen, L.M., Gui, L.G., Lv, J.L., Wang, C.G., Li, Z.Z., Wang, Z., Sun, R.: Evaluation on Soil Fertility Quality of Newly Cultivated Light Sierozem Under Different Fertilization with Methods of Principal Component and Cluster Analyses. J. Soils. 40(6), 971-975 (2008)

7. Duan, B.T., Yang, X.Y., Li, F.P., Zhao, X.H., Li, M.L., Su, S.K., Su, D.Y., Zhang, P., Liu, H.H.: Integrated Evaluation of Soil Fertility Based on Factor Analysis. J. Modern Agricultural Science and Technology. (7), 228-230 (2016)

8. Tan, X.M., Geng, Y.H., Jiang, X.B., Zhou, Y.Q.: Evaluation of Soil Fertility of Different Vegetation Types in Ruxi River Valley Based on Factor Analysis. J. Acta Agriculturae Jiangxi. 26(5), 14-18 (2014)

9. Cao, W.P., Wu, F.Q., Lei, J.Y., Zhao, L.S., Yu, X.L.: Evaluation of Soil Fertility Quality in Different Tillage Treatmentsbased on Factor Analysis--A case of the Southern Edge of the Mu Su Desert. J .Journal of Northwest A\&F University(Nat. Sci. Ed.). 39(1), 159-165 (2011)

10. Zhang ,Y.G., Shi, Y.J., Wu, Z.B.: Assessment on Soil Fertility Status of Jujube Orchards Based on Principal Component Analysis. J. Southwest China Journal of Agricultural Sciences. 29(5), 1156-1160 (2016)

11. Zhang, L.: Soil Fertility Evaluation \& Improvement Measures of Walnut Orchards in Wushi County, Xinjiang. Xinjiang Agriculture University. (2015)

12. Li ,P., Wang, P., Dai, W., Wang, D., Deng, Z.F., Zhao, C.: Evaluation of Soilfertility in Subtropical Forests. J. Journal of Beijing Forestry University. 32(3), 52-58 (2010) 